\begin{tabular}{|l|l|l|}
\hline & ESCOLA DE COMUNICAÇÃO, \\
& ARTES E DESIGN & mídia, cultura e tecnologia \\
& $\begin{array}{l}\text { Revista FAMECOS, Porto Alegre, v. 27, p. 1-14, jan.-dez. 2020 } \\
\text { e-ISSN: 1980-3729 | ISSN-L: 1415-0549 }\end{array}$ \\
\hline & \\
\hline
\end{tabular}

CINEMA

\title{
O cinema brasileiro nas telas argentinas no período dos estúdios (1933-1954)
}

The brazilian cinema in the argentine screens in the studio period (1933-1954) El cine brasileño en las pantallas argentinas en el periodo de los estudios (1933-1954)

\section{Arthur Autran Franco de Sá Neto ${ }^{2}$}

orcid.org/0000-0003-4455-8105

autran@ufscar.br

Recebido em: 29 jan. 2019 Aprovado em: 15 out. 2019 Publicado em: 28 mai. 2020
Resumo: Este artigo aborda o conjunto de longas-metragens brasileiros sonoros exibidos nos cinemas de Buenos Aires no periodo de 1933 a 1954, ou seja, quando do predomínio do estúdio como base da produção. Trata-se do resultado de uma ampla pesquisa de fontes primárias, tais como revistas e jornais, realizada em Buenos Aires. O texto tem por metodologia a historiografia do cinema. Ele objetiva descrever e analisar as caracteristicas principais de cada um dos filmes que alcançaram as telas argentinas, o seu lançamento em Buenos Aires e a repercussão na imprensa, bem como discutir os traços comuns destas produções e as suas dificuldades naquele mercado. Entre outros pontos, destaca-se a questão da língua como um entrave para a produção brasileira e a necessidade da associação entre brasileiros e argentinos para alcançar uma melhor circulação das películas.

Palavras-chave: Cinema Brasileiro. Exibição. Argentina.

\begin{abstract}
This article deals with the set of Brazilian sound feature films exhibited in Buenos Aires theaters from 1933 to 1954, that is, when the studio predominates as the production base. This is the result of extensive research from primary sources, such as magazines and newspapers, held in Buenos Aires. The text has by methodology the film historiography. It aims to describe and analyze the main characteristics of each of the films that reached the Argentine screens, its launch in Buenos Aires and the repercussion in the press, as well as discuss the common traits of these productions and their difficulties in that market. Among other points, the issue of language as an obstacle to Brazilian production and the need for the association between Brazilians and Argentines to achieve a better circulation of the films.
\end{abstract}

Keywords: Brazilian Cinema. Exhibition. Argentina.

Resumen: Este artículo aborda el conjunto de largometrajes brasileños sonoros exhibidos en los cines de Buenos Aires en el periodo de 1933 a 1954, o sea, cuando del predominio del estudio como base de la producción. Se trata del resultado de una amplia investigación de fuentes primarias, tales como revistas y periódicos, hecha en Buenos Aires. El texto tiene por metodología la historiografía del cine. Se trata de describir y analizar las caracteristicas principales de cada una de las peliculas que alcanzaron las pantallas argentinas, su lanzamiento en Buenos Aires y la repercusión en la prensa, asi como discutir los rasgos comunes de estas producciones y sus dificultades en dicho marcado. Entre otros puntos, se destaca la cuestión de la lengua como un obstáculo para la producción brasileña y la necesidad de la asociación entre brasileños y argentinos para lograr una mejor circulación de las películas.

Palabras-clave: Cine Brasileño. Exhibición. Argentina. 


\section{Introdução}

Esse artigo tem como objetivo expor pesquisa sistemática acerca da presença do filme brasileiro na Argentina no periodo de 1933 a 1954, no qual predominaram formas de produção inspiradas no sistema de estúdios tal como desenvolvido em Hollywood. ${ }^{3}$ Trata-se de indicar quais longasmetragens foram lançados comercialmente na praça de Buenos Aires, certamente a mais importante do pais, observando as principais características de cada um dos filmes brasileiros ali exibidos no periodo mencionado, o circuito de exibição, sua forma de lançamento e a repercussão junto à imprensa e ao público locais.

O recorte temporal foi fixado quanto à sua data inicial por ser o ano em que a Cinédia - então a principal companhia cinematográfica do Brasil - produziu pioneiramente no país filmes com o som impresso na película. Destarte, o som era incorporado ao processo de produção que se pretendia industrial com base em estúdio nos moldes que o cinema norte-americano havia definido, após experimentos que incluiram sistemas de som gravados em disco - e até então emulados pelos produtores brasileiros. Quanto ao marco final, no ano de 1954 ocorreu a quebra da Cia. Cinematográfica Vera Cruz, a mais importante tentativa entre nós inspirada no modelo do Studio system. Ou seja, pode-se dizer que o interregno de 1933 a 1954 compreende o cerne das tentativas de produção no Brasil de cinema sonoro com base em estúdios.

Seria de salientar que as experiências da Cinédia, da Vera Cruz e de outras empresas tinham o Studio system mais como ideal a ser alcançado e/ou horizonte ideológico. Entretanto, suas práticas concretas destoavam em muitos pontos do modelo.

O número total de fitas lançadas comercialmente em Buenos Aires foi muito pequeno para tão largo interregno de tempo, somando apenas cinco longas-metragens do total de 288 realizados. ${ }^{4}$ No que pese a debilidade do cinema brasileiro de então, afigura-se uma quantidade bem restrita, ademais que, como veremos, algumas ausências chamam atenção.

Neste sentido, buscarei também apontar para os motivos das dificuldades de acesso do filme brasileiro ao mercado argentino no período, para além da fragilidade estrutural da nossa cinematografia.

Como principal fonte primária de pesquisa utilizei o periódico Heraldo del Cinematografista, secundado pelo diário La Nación - este último então o mais respeitado jornal da Argentina. Eventualmente alguns outros periódicos foram utilizados para a complementação de informações.

Devido à sua importância para este artigo, merece apresentação o Heraldo del Cinematografista. Tratava-se de uma publicação semanal voltada para o comércio cinematográfico da Argentina. Ela registrava todos os lançamentos comerciais de longas-metragens em Buenos Aires. Além da ficha técnica, resumo do enredo, pequeno comentário sobre a obra e algumas frases para divulgação do filme, o periódico atribuia notas pelo "Valor Comercial", "Valor Artístico" e "Valor Argumento" - que eram cotadas de um a cinco. Ademais, publicava informações, artigos analíticos e enquetes sobre a produção, a distribuição e exibição. Seu editor durante aqueles anos era o respeitado jornalista Israel Chas de Cruz, criador da publicação. Foram levantadas para a pesquisa quase todas as edições do Heraldo del Cinematografista desde 1933 até 1954, faltando alguns poucos números não encontrados nas bibliotecas.

O cinema na capital argentina nos anos 1930 era mais uma das atrações da florescente indústria cultural do país. A produção cinematográfica local cresceu até o início do decênio seguinte, alcançando o posto de principal produtor latinoamericano. Tratava-se, nas palavras de Domingo di Núbila (1998), da "época de ouro". O mercado exibidor também era forte e, mesmo com a importante produção argentina, era dominado

\footnotetext{
Para uma discussão aprofundada sobre o sistema de estúdios de Hollywood consultar o fundamental The classical Hollywood cinema: film style \& mode of production to 1960 (1985), de David Bordwell, Janet Staiger e Kristin Thompson.

4 Para chegar à soma de 288 longas-metragens produzidos entre 1933 e 1954 foram calculados por mim os totais anuais apresentados por Randal Johnson (1987, p. 201).
} 
pelo filme norte-americano. O predomínio de Hollywood marcou todo o periodo analisado.

Consegui levantar em Heraldo del Cinematografista o lançamento comercial em Buenos Aires dos seguintes longas-metragens brasileiros: Noches cariocas, El grito de la juventud, Canta Brasil, Mundo extraño e No me digas adiós. A exposição seguirá a ordem cronológica das estreias na cidade.

\section{Noches cariocas}

O primeiro filme sonoro brasileiro lançado comercialmente em Buenos Aires foi Noches cariocas (Noites cariocas, 1935). ${ }^{5}$ A pelicula tinha no elenco os argentinos Carlos Viván, Maria Luisa Palomero e Carlos Perelli, além dos brasileiros Lodia Silva, Mesquitinha, Oscarito e Grande Otelo. O diretor foi o argentino Enrique Cadícamo, que se notabilizou como compositor das letras de alguns dos tangos mais conhecidos como Anclao en Paris ou Pompas de jábon, entre outros. A produção foi da empresa brasileira Uiara Filmes e o financiamento de Caio Caldeira Brant, o proprietário do Cassino da Urca.

Em seu livro de memórias intitulado Bajo el signo del tango. Cadicamo dedica algumas páginas a Noches cariocas. Do lado pessoal, atribui a experiência à sua paixão pelo cinema, já tendo realizado em Buenos Aires a película $L a$ virgencita de Pompeya (1935). A oportunidade de dirigir no Brasil surgiu por meio do convite de seu amigo Carlos Viván, o qual fazia sucesso como cantor no Cassino da Urca e havia convencido Caio Caldeira Brant a investir em um filme.

As dificuldades foram enormes, pois a Cinédia, estúdio utilizado para a produção, demonstrouse decepcionante quando comparada aos congêneres argentinos. Mas, felizmente, Cadicamo reencontrou no Rio de Janeiro Adam Jacko e Ciabarra, técnicos que estavam ali tentando a sorte e participaram da equipe de
La virgencita de Pompeya, respectivamente como assistente de fotografia e técnico de som. Foi necessário importar insumos de Buenos Aires, ademais, Jacko - que assumiu a fotografia do filme - e Ciabarra ${ }^{6}$ - o técnico de som - tiveram de preparar equipamentos.

Cadicamo voltou a Buenos Aires logo após Noches cariocas ficar pronto e ser projetado para jornalistas e exibidores (CADÍCAMO, 1987, p. 141143 e 148). No que pese os muitos anos entre os fatos e a escrita das memórias, bem como o tom algo narcisista da narrativa, ficam patentes as condições técnicas precárias do cinema brasileiro e os problemas de toda ordem que dai decorriam.

Noches cariocas era uma comédia musical com uma história que girava em torno de uma argentina (Maria Luisa Palomero) namorada de um aristocrata golpista (Carlos Perelli), mas, no Brasil, ela reencontra seu antigo amor, um cantor (Carlos Viván) que consegue fazer sucesso no Rio de Janeiro, onde os dois voltam a ficar juntos. A película era falada em português e castelhano e certamente buscava alcançar o mercado dos dois países. As músicas iam do tango Mis noches de champagne - de Juan Carlos Cobián, interpretada por Carlos Viván - até Luar do sertão - de Custódio Mesquita, interpretada por Singing Babies. Ao que se saiba não existem mais cópias do filme.

A primeira nota de Heraldo del Cinematografista a respeito de Noches cariocas indica que a fita estrearia em setembro de 1935 e se tratava de uma "[...] película de ambiente e idioma argentinobrasileiro".7 (INDUSTRIA, 1935, p. 1003). Mas, só em 23 de dezembro o filme entrou em cartaz nos cinemas American Palace e Astral por meio da distribuidora Panamericana Films.

Através de La Película, pode-se confirmar que a fita tinha diálogos nas duas línguas (ENEBE, 1935, p. 6). Na sua avaliação, Heraldo del Cinematografista considerou desagradável a mistura do português com o castelhano. Ademais, o filme recebeu

\footnotetext{
5 Em Buenos Aires foi exibido sem caráter comercial pelo menos um filme brasileiro sonoro antes de Noches cariocas. Trata-se de Carioca maravilhosa (Luiz de Barros, 1935), exibido em junho de 1935 como homenagem a Getúlio Vargas, o qual visitara a Argentina pouco antes (MARIÑO, 2016, p. 160).

6 Na Filmografia Brasileira, da Cinemateca Brasileira, a grafia do nome do responsável pelo som de Noites cariocas é Genaro Ciavarra Disponivel em: http://bases.cinemateca.gov.br/cgi-bin/wxis.exe/iah/?IsisScript=iah/iah.xis\&base=FILMOGRAFIA\&lang=p\&nextAction=lnk\&exprSearch=ID=003825\&format=detailed.pft\#1. Acesso em: 18 dez. 2018.

7 Do original: "I...] película de ambiente e idioma argentino-brasileño."
} 
cotações muito baixas deste periódico. O Valor Comercial mereceu nota um e meio, seu Valor Artístico também um e meio e o Valor Argumento foi considerado ainda menor: um.

Os comentários críticos foram bastante negativos, como já deixam perceber as cotações: 0 som e a fotografia eram considerados deficientes, a direção seria irregular, as interpretações dos artistas fracas e nem as músicas teriam grande valor. Para o semanário, salvavam-se algumas situações cômicas, bem como cenas com o carnaval e as paisagens do Rio de Janeiro (NOCHES, 1936, p. 1092-1093).

A crítica de autor anônimo publicada em La Nación é ainda mais dura com Noches cariocas, filme que, comparativamente, estaria bem abaixo da produção argentina. A fita possuiria: "Um argumento ilógico, uma interpretação mediocre, uma fotografia e um som defeituosos caracterizam este 'filme', cuja direção tampouco indica maiores acertos"8 (PELICULA, 1935, p. 12).

O desempenho comercial de Noches cariocas também não foi bom, pois, lançado em duas salas de pouco importância - as referidas Astral e American Palace -, já no dia 26 de dezembro saira de cartaz. Mesmo a presença de Carlos Viván encabeçando o elenco não foi capaz de atrair o público, até porque, segundo a pesquisadora Cecilia Nuria Gil Mariño (2016, p. 162), nesse momento o cantor e ator já estava distanciado do público local.

\section{El grito de la juventud}

O segundo filme lançado comercialmente em Buenos Aires no recorte pesquisado foi El grito de la juventud (1936), de Raul Roulien, ator, dançarino e cantor de sucesso nos palcos brasileiros que passou por Hollywood nos anos 1930. Em meados desta década, ele retornou ao Brasil e, com O grito da mocidade (1936), deu início à sua carreira como diretor.
Ainda nos anos 1920, Roulien passou algum tempo pelos palcos portenhos integrando as atrações de espetáculos de variedades. Posteriormente, seu nome circulava na Argentina devido à sua presença como ator em diversas produções de Hollywood, entre elas filmes de destaque como Flying down to Rio (Thornton Freeland, 1933), exibido na Argentina com o título de Volando a Río. Muitas das películas norteamericanas com Roulien eram em espanhol, é o caso, por exemplo, do policial Eran 13 (David Howard, 1931), uma versão de Charlie Chan carries on (Hamilton MacFadden, 1931). ${ }^{9}$ É possivel afirmar que era um artista conhecido pelo público local.

Em reportagem publicada pela revista Cinegraf, Roulien expôs suas ideias acerca da indústria cinematográfica:

\begin{abstract}
Um estúdio na América do Sul deve ser como um estúdio em Hollywood. Um filme deve ser em forma, luz e som a expressão total das conquistas alcançadas. O filme falado em castelhano e em português deve ser produzido, em primeiro lugar, por nós mesmos. E se, do ponto de vista artístico, sabemos realizar nosso espetáculo, do ponto de vista econômico isso representaria a porta aberta em outros paises ${ }^{10}$ (FABREGAT, 1936, p. 29).
\end{abstract}

A maior parte das colocações de Roulien não discrepa do que era o pensamento industrial cinematográfico brasileiro de então: tratar-seia de emular Hollywood em termos técnicos e estéticos a fim de alcançar o público, buscando a melhor qualidade possivel por meio da produção de estúdio. Adhemar Gonzaga e Pedro Lima já vinham expondo essas ideias desde os anos 1920. A diferença, que aumenta as dificuldades inerentes ao projeto, é o fato de se produzir em duas línguas e não apenas uma. Ou seja, não se tratava de alcançar apenas o próprio pais, mas buscar comercializar as fitas em outros mercados do subcontinente latino-americano.

\footnotetext{
8 Do original: "Un argumento ilógico, una interpretación mediocre, una fotografía y un sonido defectuosos caracterizan a este 'film', cuya dirección tampoco acusa mayores aciertos."

9 Com o advento do som, e a necessidade de compreensão dos filmes falados em inglês por plateias que não dominavam esta língua foram desenvolvidos meios de tradução como a dublagem e as legendas. Também foram produzidos em Hollywood filmes em línguas como o espanhol e o francês, o que incluiu versões da produção original em inglês.

10 Do original: "Un estudio en Sud América debe ser como un estudio en Hollywood. Una película debe ser en figura, luz y sonido la expresión total de las conquistas alcanzadas. La pelicula hablada en castellano y en portugués debe ser producida en primer término por nosotros mismos. Y si desde el punto de vista artístico sabemos realizar nuestro espectáculo, desde el punto de vista económico eso representaría la puerta franca en otros paises."
} 
E Roulien tentou colocar suas ideias em prática por meio da realização conjunta de O grito da mocidade e El grito de la juventud. Destarte. ele desenvolveu um tipo de produção do qual participou em Hollywood na qualidade de ator e que visava justamente atingir mercados de línguas diferentes por meio da feitura de diversas versões cinematográficas. Ou seja, não se tratava de um só filme, mas de duas versões com base no mesmo roteiro rodadas no Rio de Janeiro no primeiro semestre de 1936. O grito da mocidade era falado em português, foi dirigido e estrelado pelo próprio Roulien, tendo ao seu lado Conchita Montenegro e os atores brasileiros Jaime Costa, Manoel Pera e Jorge Murad. El grito de la juventud, a versão em castelhano, foi dirigida por Roulien, contava com os mesmos técnicos, além dele e Conchita Montenegro encabeçando o elenco, completado pelos artistas argentinos Lalo Malcolm, Vicente Climent e Maria Luisa Palomero, entre outros, que vieram de Buenos Aires para filmar no Rio de Janeiro (CINEMA, 1936, p. 22).

No segundo semestre de 1936, Roulien foi a Buenos Aires acompanhado por Conchita Montenegro para apresentações em palcos portenhos e pelas ondas da Rádio Belgrano (EL EDITOR, 1936, p. 1187), aproveitando a estadia para finalizar as duas versões (EL EDITOR, 1936, p. 1287). A revelação, a montagem e a sonorização de ambas foram efetuadas na Argentina, nos estúdios da Side, empresa que também distribuiu El grito de la juventud (AYER, 1939, p. 13).

Segundo observa Cecilia Nuria Gil Mariño (2016, p. 202 e 204-205), a produção de O grito da mocidade despertou grandes esperanças na imprensa brasileira. Segundo a pesquisadora, o jornal O Imparcial considerou que a obra seria "um superfilme brasileiro", primeiro produto da "Hollywood Carioca". Mas, uma vez apresentado comercialmente no Rio de Janeiro em novembro de 1936, o filme em geral recebeu críticas negativas, pois tanto A Scena Muda quanto O Imparcial criticaram a direção e a primeira publicação também fez reservas ao que entendeu como excesso de apelo ao patriotismo.

El grito de la juventud, a versão em castelhano, estreou em Buenos Aires somente em 05 de outubro de 1939 nos cinemas General Mitre, Príncipe, Ritz, Coliseo Palermo, Cóndor, National de Santa Fé e Roxy, todos localizados fora da região central (CUATRO, 1939, p. 14). Ou seja, cerca de três anos depois da sua finalização e da estreia da versão brasileira no Rio de Janeiro. Side chegou a fazer publicidade, anunciando o filme no periódico voltado para o comércio cinematográfico La Película, em 28 de setembro de 1939. O anúncio salienta o nome Roulien como diretor e ator, bem como a presença de músicas brasileiras, mas não menciona a origem da produção.

A trama de El grito de la juventud foi resumida por Heraldo del Cinematografista da seguinte forma: "A enfermidade de uma moça força o adiamento do seu casamento e o noivo, estudante de medicina, só então percebe a responsabilidade da sua carreira. Episódios da vida do hospital completam o filme"11 (GRITO, 1939, p. 160).

Heraldo del Cinematografista foi contundente na sua crítica da fita, a qual mereceu cotação nota dois em todos os itens analisados pelo periódico. Além da técnica ser considerada problemática, o desenvolvimento da trama causaria pouco interesse pelos saltos e o argumento seria "confuso", salvando-se somente as cenas que mostravam as situações relativas ao hospital (GRITO, 1939, p. 160). A crítica de La Nación também avaliou negativamente o desenvolvimento da trama bem como o excesso de diálogos, mas observou que há "[...] momentos com ligeira eficácia, lao tratar] a vida em um internato de medicina no Rio de Janeiro"12 (AYER, 1939, p. 13). Porém, La Película apresentou uma análise mais positiva, aduzindo que a fita possuía "[...] graça e simpatia em suas cenas humorísticas"13 e os números musicais seriam agradáveis, criticando tão somente o tom melodramático das partes que se pretendiam sérias (8, 1939, p. 6).

\footnotetext{
11 Do original: "La enfermedad de una muchacha obliga a la postergación de su casamiento y el novio, estudiante de medicina, recién entonces advierte la responsabilidad de la carrera. Episodios de la vida de hospital completan el film".

12 Do original: ".... momentos con ligera eficacia, la vida en un internato de medicina en Río de Janeiro".

13 Do original: "[...] gracia y simpatía en sus escenas humoristicas".
} 
A única referência encontrada quanto ao desempenho de público de El grito de la juventud provem de uma nota saída na revista Cine Argentino, na qual afirma que a película obteve êxito na estreia (LA PEÑA, 1939, p. 70). No entanto, o visível tom publicitário da nota faz com que se possa ter dúvidas acerca da sua veracidade.

\section{Canta Brasil}

A Segunda Guerra Mundial marcou uma longa interrupção no lançamento de filmes brasileiros no mercado portenho. Somente em 1946 ocorreu uma nova estreia em Buenos Aires e desta feita de um gênero que já estava instituido como o principal em termos comerciais para o cinema brasileiro: a comédia musical de fatura rápida, também conhecida como chanchada.

Com o título de Canta Brasil foi lançada a produção da Atlântida no dia 20 de dezembro em pleno cine Monumental, a casa das grandes estreias do cinema argentino. O título original do filme é Segura esta mulher (1946), direção de Watson Macedo e com o elenco integrado por Marion, Catalano, Hortênsia Santos, Grande Otelo e Mesquitinha, bem como números musicais de Orlando Silva, Nelson Gonçalves e Aracy de Almeida, dentre outras atrações. No Rio de Janeiro, a fita estreou em fevereiro de 1946, constituindo-se em um grande sucesso de público.

A exibição de Canta Brasil em Buenos Aires contou com publicidade em La Nación. Os anúncios, publicados nos dias 19 e 20 de dezembro, apresentam Marion vestida de baiana - referência evidente a Carmem Miranda - e uma legenda que busca chamar atenção para a vibração do carnaval que se faria presente na fita.

A trama, como de costume nas chanchadas, é caracterizada por muitos números musicais e uma série de confusões, cujo marco inicial é a briga de um casal em decorrência da qual a mulher (Hortência Santos) sai de casa. O marido (Catalano) contrata o atrapalhado detetive Olho Vivo (Grande Otelo) para encontrá-la. Por equívoco, Olho Vivo toma a personagem de Marion pela esposa e leva o marido a uma boate, como o marido acha que sua mulher fez plástica, acaba acreditando que Marion é a própria. Ela finge aceitar a situação, pois um louco (Mesquitinha) escapou do hospicio e fica furioso quando é contrariado. Ao final, o louco é identificado e levado para o hospício, o equívoco se esclarece e marido e mulher reencontram-se.

Em relação a Canta Brasil, exibido com legendas em espanhol, Heraldo del Cinematografista não atribuiu suas tradicionais notas. A critica do semanário não foi positiva, comparando a película brasileira quanto ao argumento e à técnica com a produção argentina Dancing, filme de Luis José Moglia Barth datado de 1934, ou seja, mais de dez anos antes. Fotografia, iluminação e som foram avaliados como irregulares, a direção seria de alguém inexperiente e a narrativa mereceu o mesmo tipo de reprovação da crítica brasileira acerca das chanchadas em geral, a saber, de apresentar uma série de números típicos do teatro de revista. Grande Otelo e Marion são exceções, ele foi considerado muito gracioso e ela teria ótima voz, as músicas também foram qualificadas como agradáveis (CANTA, 1946, p. 229).

Já La Nación, no que pese indicar o desequilibrio da parte técnica da fita e de ela ter sido realizada com poucos recursos, publicou uma análise mais positiva de Canta Brasil, ao destacar a agilidade dos diálogos e que o público a recebera bem (CANTA, 1946, p. 12). Na nota crítica de La Nación chama atenção ainda a observação para o fato de que Canta Brasil apresentava um "prólogo" no qual se anunciava "[...] que o filme não tem outro propósito do que mostrar ao público da América Latina uma seleção de números musicais populares".14

É curioso notar que Romance no Rio (Caminito de gloria, Luis César Amadori, 1939), película argentina estrelada por Libertad Lamarque, quando foi exibida comercialmente no Brasil, em 1940, também possuia uma espécie de introito em que a cantora e atriz dedicava a obra ao público deste pais (AUTRAN, 2016, p. 147). A consciência de produtores e distribuidores acerca do diferencial desses produtos em mercados dominados por

14 Do original: "[...] que el film no tiene más propósito que mostrar al público de Latinoamérica una selección de números musicales populares". 
Hollywood aparentemente levava à necessidade de um tipo de apresentação do filme, de uma explicação a seu respeito. Parece se tratar de uma forma de introduzir espectadores que não estavam acostumados com aquele tipo de produto.

\section{Mundo extraño}

Mundo extraño é um filme dirigido por Francisco Eichorn, imigrante alemão que se estabeleceu no Brasil. Trata-se de uma coprodução no sentido de que sua realização envolveu capitais e esforços de empresas de três países: a brasileira Astra Filmes, a argentina Estudios San Miguel e a alemã Constantin Film Produktion (SILVA, 2014, p. 122). O título da película no Brasil, quando do seu primeiro lançamento em 1950, era Mundo estranho, mas ao ser relançado comercialmente nos anos 1960 foi alterado para A grande aventura amazônica.

Estudios San Miguel foi a produtora argentina que mais decididamente procurou entrar no mercado brasileiro no chamado período clássico do cinema. A empresa tinha como principal acionista o milionário Miguel Machinandiarena. Desde meados de 1942, o próprio Machinandiarena ou representantes da produtora vinham ao Brasil para divulgar os filmes dos Estudios San Miguel, fazer contatos com o meio cinematográfico e também com autoridades do governo. Em 1943. foi instituida no Rio de Janeiro a distribuidora São Miguel do Brasil (KOHEN, 2000, p. 352-353).

A crise do cinema argentino acarretada pela Segunda Guerra Mundial esvaziou a tentativa dos Estudios San Miguel de aproximação em relação ao Brasil. No entanto, após o conflito mundial se encerrar, a empresa voltou a buscar formas de penetração no mercado brasileiro.

Em meados de 1948, surgiram noticias na imprensa argentina a respeito de Mundo extraño. Heraldo del Cinematografista informava que os exteriores da fita haviam sido rodados no Amazonas e os interiores seriam filmados nos estúdios da San Miguel, localizados na Argentina (PRODUCCIÓN, 1948, p. 103). A montagem e a finalização também ocorreram na San Miguel.
Em nota publicada no final do ano, no mesmo periódico, Mundo extraño foi listado entre os filmes da empresa programados para estrear em 1949 (12, 1948, p. 264). Mas, depois deste anúncio, a película sumiu por alguns meses do radar da imprensa argentina, possivelmente em decorrência das graves dificuldades financeiras que a produtora enfrentou ao longo de 1949.

Mundo extraño estreou somente a 10 de maio de 1950, no cine Normandie, tendo sido precedido por boa campanha publicitária. Podem ser encontrados anúncios da fita nos diários Crítica, El Mundo e La Nación.

Mundo extraño é um filme de aventuras em torno das peripécias de Edgar (Alexandre Carlos), jovem que, depois de alguns anos, resolve voltar à selva amazônica para achar seu pai e o Deus de Ouro, peça de grande valor pertencente a índios que caçam cabeças. Edgar enfrenta muitos perigos na selva e reencontra a bela Elisa (Angelika Hauff), que em criança também partira com a expedição. Do reencontro, nasce a paixão entre os dois.

É de se notar que, além de material de claro viés ficcional - pois há atores, iluminação artificial, estúdios, etc. -, existe também material documental que se mescla na montagem ao primeiro. São imagens de indigenas, de paisagens naturais e de animais de diversos tipos. Conforme veremos, este será um aspecto destacado pela crítica.

Antes de passar à recepção da crítica, é de salientar que Mundo extraño foi um sucesso de bilheteria, em realidade o único caso do nosso corpus. Heraldo del Cinematografista previu as possibilidades comerciais da fita atribuindo nota quatro para o seu Valor Comercial - além de três e meio para o Artístico e três para o Argumento -, embora observasse que o público seria de "Populares" (MUNDO, 1950, p. 85).

Quanto à crítica, houve certo entusiasmo do Heraldo del Cinematografista em relação à película. Foram analisadas negativamente a frouxidão do seu início, bem como algumas partes da narrativa por serem demasiado compridas; por outro lado, considerava-se que era o "[...] o 
mais completo dos filmes de aventuras na selva que vimos nos últimos anos". ${ }^{15} \mathrm{~A}$ parte positiva da avaliação decorria, em primeiro lugar, do material documental, o qual registrava indigenas, bem como diversos tipos de animais. Outrossim, salientava-se que este conteúdo era apresentado de maneira articulada em uma narrativa ficcional. Direção, montagem, som e música foram bastante elogiados e mesmo a fotografia, apesar de irregular, possuiria muita qualidade. Ou seja, a parte técnica foi analisada de maneira positiva, algo que Heraldo del Cinematografista nunca havia julgado em relação aos outros longas-metragens brasileiros. Os astros do filme, Alexandre Carlos e Angelika Hauff, também mereceram elogios. Para concluir, o periódico aduziu que:

Em resumo, Mundo estranho pode ser comparado vantajosamente com a maioria das aventuras na selva que Hollywood geralmente oferece, e constitui algo completamente à parte no contexto do cinema argentino; ademais, assinala que nossa tela pode sacar proveito das combinações de valores internacionais ${ }^{16}$ (MUNDO, 1950, p. 85).

No parágrafo acima duas questões afiguramse como importantes. A primeira diz respeito à comparação com Hollywood, ou seja, de que a indústria argentina poderia oferecer ao seu público, pelo menos em relação a alguns gêneros, filmes tão bons ou até melhores do que os de Hollywood. Deve-se considerar que este era um momento de forte protecionismo ao cinema argentino. A segunda questão diz respeito à colaboração internacional, pois, como indiquei anteriormente, Estudios San Miguel buscava há anos se aproximar do mercado brasileiro e isto se desdobrou inclusive em coproduções. O periódico avaliou positivamente esse trabalho conjunto com brasileiros, como o músico Walter Schultz Porto
Alegre, ou pessoas de outras nacionalidades radicadas no Brasil, como eram os casos dos alemães Francisco Eichorn e Edgar Eichorn irmão do primeiro e fotógrafo do filme - ou da austriaca Angelika Hauff.

As imagens documentais impressionaram o crítico King, o qual pelas páginas de El Mundo reinventou a geografia:

Tem o atrativo da coisa autêntica no que se refere ao reino animal e vegetal. Mundo estranho, filmado onde os Andes caem abruptamente sobre a selva brasileira, possui o atrativo do cenário natural, selvagem. E sobre ele, crocodilos, macacos, serpentes, piranhas e pássaros. E, por momentos, tribos de indios dedicadas aos seus ritos $^{17}$ (1950, p. 11).

Para ademais do erro de considerar que os Andes chegam ao Brasil, fica patente no texto a atração pelo exótico, pelo outro considerado como algo totalmente diferente e ameaçador. o único comentário encontrado por mim que problematiza o modo como o material documental é utilizado no filme foi publicado de forma anônima na revista Mundo Radial:

[...] é uma típica história de aventuras de tipo tarzaniano, que interessa ao espectador pelo desfile de animais exóticos, pássaros raros e tribos selvagens, mas que do ponto de vista histórico-geográfico é um constante despropósito, já que se mesclam caprichosamente regiões e lendas que não têm nenhum parentesco ${ }^{18}$ (MUNDO, 1950, p. 45).

Ou seja, Mundo extraño faz uma enorme confusão entre diferentes regiões da América do Sul, os povos indigenas que as habitam e suas respectivas tradições.

Da minha perspectiva, o modo como o filme representa a região amazônica, seus habitantes, sua fauna e sua flora é de maneira a reforçar

\footnotetext{
15 Do original: "[...] más completo de los films de aventuras en la selva que hemos visto en los últimos años".

16 Do original: "En suma Mundo extraño puede compararse ventajosamente con la mayoría de las aventuras selváticas que suele ofrecer Hollywood, y constituye algo completamente aparte dentro del cine argentino; es más, señala que nuestra pantalla puede sacar provecho de las combinaciones de valores internacionales".

17 Do original: "Tiene el atractivo de la cosa auténtica en lo que al reino animal y vegetal se refiere. Mundo extraño, filmada donde los Andes caen abruptamente sobre la selva brasileña, posee el atractivo del escenario natural, salvaje. Y sobre él, cocodrilos, monos, serpientes, pirañas, pájaros. Y, por momentos, tribus de indios entregadas a sus ritos."

18 Do original: "[...] es un típico relato de aventuras de tipo tarzanesco, que interesa al espectador por el desfile de animales exóticos, pájaros raros y tribus salvajes, pero que desde un punto de vista histórico-geográfico es un constante contrasentido, ya que se mezcla caprichosamente regiones y leyendas que no tienen ningún parentesco."
} 
na tecla do exotismo, do estranho e do perigo, apresentados na fita por meio de ataques de jacarés e piranhas ou ainda dos rituais e crenças indigenas que envolveriam sacrificios humanos. Importante notar que as cenas de violência por parte dos indigenas são todas de origem ficcional, mas não se atenta para isto nas críticas que levantei.

\section{No me digas adiós}

No mesmo ano de 1950, Estudios San Miguel lançou em Buenos Aires outra coprodução com o Brasil: No me digas adiós (Não me digas adeus, 1949), dirigida por Luis José Moglia Barth. Desta feita, a coprodução envolvia sua filial no país, São Miguel do Brasil.

A fita foi divulgada em 1948 inicialmente com o título de Quitandinha ${ }^{19}$ e Heraldo de Cinematografista noticiou que Moglia Barth viajou com uma equipe para filmar no Rio de Janeiro essa película (PRODUCCIÓN, 1948, p. 9). Algumas edições depois, informou-se que Copacabana, o carnaval e o hotel Quitandinha foram filmados para Bajo el cielo del Brasil, que contava no elenco com os argentinos Nelly Daren, Josefina Díaz e Manuel Collado e o brasileiro Anselmo Duarte (PRODUCCIÓN, 1948, p. 41). Finalmente, anunciouse que a produção mudou de título para No me digas adiós (PRODUCCIÓN, 1948, p. 72).

Em fins de 1948, ela era listada como um dos lançamentos de Estudios San Miguel para o ano seguinte, tal como Mundo extraño (12, 1948, p. 264). Mas, também no caso da fita de Moglia Barth, a situação dificil da produtora acarretou demora na estreia em Buenos Aires, a qual ocorreu apenas a 10 de outubro de 1950 no cine Broadway, havendo alguma publicidade em La Nación e em El Mundo.

Os anúncios publicitários enfocam, sobretudo, o nome de Nelly Daren, a temática do carnaval carioca e os ritmos dos números musicais, tais como samba e tango. O anúncio, publicado pelo jornal El Mundo no dia do lançamento, tinha como dizeres "Um cordial abraço cinematográfico entre Argentina e Brasil".20

A trama dessa comédia romântica envolve dois jovens que se conhecem em uma universidade norte-americana e apaixonam-se, o brasileiro Guaraci (Anselmo Duarte) e a argentina Mercedes (Nelly Daren). Ocorre que ambos têm namorados em seus respectivos países e, ao retornar à América do Sul, devem convencer suas famílias da nova situação. Após uma tratativa, ambas as familias se hospedam no hotel Quitandinha e lá tudo se resolve. A parte musical ficou a cargo de Linda Batista e do conjunto Quitandinha Serenaders. Tal como Noches cariocas, era mais uma experiência de um filme falado em castelhano e em português.

É difícil precisar a repercussão de público de No me digas adiós. Heraldo del Cinematografista concedeu nota três para o Valor Comercial da fita, ademais de três para o Artístico e dois para o Argumento (NO, 1950, p. 253). O filme conseguiu superar sua primeira semana de exibição no cine Broadway continuando em cartaz, indício de que a bilheteria não foi ruim.

Quanto à repercussão na imprensa, Heraldo del Cinematografista entendia que era boa a iniciativa de se produzir cinema juntando elementos da Argentina e do Brasil e não havia incômodo no fato de o filme ser falado em duas linguas. Desta forma, No me digas adiós "[...] deixa aberto o caminho para obras similares que podem facilitar a conquista do mercado brasileiro para o nosso cinema". ${ }^{21}$ Mas, o filme não impressionou, pois seu argumento era pouco consistente e a narrativa "oscilante". Além disso, os números musicais teriam sido filmados de maneira descuidada.

Entre os artistas, apenas o brasileiro Darcy Cazarré foi elogiado pela simpatia do seu personagem - o pai de Guaraci. Tratava-se apenas de "[...] um amável passatempo familiar".22 Menos indulgente é a crítica publicada por La Razón, que,

\footnotetext{
19 Trata-se de uma referência ao hotel Quitandinha, um dos mais luxuosos do Brasil quando da realização do filme e que se localizava na cidade serrana de Petrópolis, no estado do Rio de Janeiro.

20 Do original: "Un cordial abrazo cinematográfico de Argentina y Brasil".

21 Do original: "[...] deja expedita la senda para obras similares que pueden facilitar la conquista del mercado brasileño para nuestro cine."
}

22 Do original: "[...] un amable pasatiempo familiar." 
apesar de reconhecer o mérito da película como um meio de confraternização entre os dois paises, considerava a narrativa de pouco interesse e o seu desenvolvimento inconsistente, ainda que o argumento fosse de Joracy Camargo, pois se recorda que ele é o autor de Deus lhe pague, peça de grande circulação no Brasil e na Argentina. Também a direção de Moglia Barth foi criticada, pois as belezas do Rio de Janeiro e o luxo do Quitandinha estavam presentes no filme, mas o carnaval foi mostrado de forma descarnada. Finalmente, em relação ao elenco, a participação da maioria dos atores foi apreciada, com exceção de Anselmo Duarte (COMEDIA, 1950).

Com esta recepção fria por parte da crítica da Argentina, Estudios San Miguel encerrava suas tentativas de coproduzir filmes com o Brasil.

\section{Reflexões acerca da presença (e da ausência) do cinema brasileiro no mercado argentino}

Como pudemos observar, a presença do cinema brasileiro no período de 1933 a 1954 foi bastante reduzida no mercado de Buenos Aires. É de se notar que a participação da produção argentina no mercado brasileiro, com destaque para Rio de Janeiro e São Paulo, foi bem maior no mesmo período, o que incluiu a instalação de pelo menos uma distribuidora entre nós - conforme apontei antes -, além do lançamento mais ou menos regular de filmes daquele país. ${ }^{23}$

Para melhor compreender a problemática do cinema brasileiro no mercado argentino entre 1933 e 1954 faz-se necessário estabelecer dois periodos: o primeiro de 1933 a 1950, o segundo de 1951 a 1954.

Parece-me evidente quanto ao primeiro período, de 1933 até 1950, que a presença rarefeita limitada a cinco longas-metragens está ligada à debilidade industrial da produção brasileira, o que também acarretava dificuldades quase insuperáveis em termos comerciais de distribuir os filmes no exterior e exibi-los, bem como a uma consciência de que os esforços deveriam ser voltados para o avanço no mercado interno.
Note-se que a maioria dos longas-metragens brasileiros exibidos em Buenos Aires em geral foram muito criticados pela imprensa local em relação aos aspectos técnicos - refiro-me a Noches cariocas, El grito de la juventud e Canta Brasil. Já Mundo extraño e No me digas adiós eram coproduções com Estudios San Miguel e lograram um padrão técnico considerado bom pelos críticos.

Outrossim, ao constatar que apenas as coproduções dos Estudios San Miguel alcançaram padrão técnico aceitável, não se deve extrapolar e pensar que somente com a contribuição de uma empresa estrangeira um filme brasileiro conseguiria atingir determinados niveis de qualidade. Basta lembrar de uma produção da Cinédia como Bonequinha de seda (Oduvaldo Vianna, 1936), que alcançou grande sucesso de público e de crítica no Brasil. E, no que pese o fato de Oduvaldo Vianna ter vindo trabalhar em rádio e cinema em Buenos Aires, entre 1938 e 1940, chegando mesmo a dirigir a película argentina O homem que nasceu duas vezes (El hombre que nació dos veces, 1938), a fita da Cinédia não foi exibida comercialmente na cidade.

Ou seja, há outros fatores em jogo que também explicam as dificuldades do cinema brasileiro no mercado argentino. Entre eles, a questão da língua ganha destaque. Isto é, o fato de o filme ser falado em português, hipoteticamente afastaria os espectadores e, portanto, distribuidores e exibidores não se interessavam pelas fitas brasileiras. Dos cinco filmes lançados comercialmente, só um era integralmente falado em português: Canta Brasil - o qual foi exibido com legendas. Já El grito de la juventud era uma versão falada em castelhano, Mundo extraño foi dublado nesta lingua e Noches cariocas e No me digas adiós eram falados em português e castelhano.

Muito cedo o entrave da língua foi notado por um produtor com grande tino comercial e sem muitos pruridos técnicos ou estéticos: Wallace Downey. Chas de Cruz, editor do Heraldo del Cinematografista, registrou que, na opinião de Downey, não valia a pena trazer para Buenos

23 Para maior análise sobre a presença do cinema argentino no mercado brasileiro ver o artigo "A guerra gaúcha: o cinema argentino no Brasil (1935-1945)" (AUTRAN, 2016). 
Aires sua última produção de enorme sucesso, Alô! Alô! Brasil (Wallace Downey, João de Barro, Alberto Ribeiro, 1935). Ele pretendia produzir na Argentina e anunciava para breve a realização de dois filmes - o que nunca se concretizou (EL EDITOR, 1935, p. 1009). Note-se que Downey emitiu essa opinião antes mesmo da estreia em Buenos Aires de Noches cariocas.

A fim de reforçar a hipótese das dificuldades acarretadas pela lingua, note-se que, entre 1933 e 1954, foram lançados comercialmente em Portugal doze longas-metragens brasileiros ${ }^{24}$, ou seja, mais do dobro dos lançamentos na Argentina. Do total de doze, oito filmes estrearam entre 1933 e 1950. Uma última observação: nenhuma das cinco produções brasileiras lançadas na Argentina foi exportada para Portugal.

Mesmo a música brasileira, presente de maneira marcante em quatro dos cinco filmes - e aqui a exceção é Mundo extraño -, não foi capaz em geral de agregar maior aceitação de público e crítica - a qual analisa de maneira negativa muitas das atrações musicais das produções exibidas em Buenos Aires. Nesse sentido, é ainda de se registrar que houve esforço da UCB (União Cinematográfica Brasileira), distribuidora ligada ao poderoso Luiz Severiano Ribeiro Júnior - dono da maior cadeia de exibição do Brasil e da Atlântida -, em lançar a chanchada Carnaval de fuego (Carnaval no fogo, Watson Macedo, 1949), mas sem conseguir realizar tal intento. ${ }^{25}$

Para furar as barreiras impostas ao cinema brasileiro, quatro dos cinco longas-metragens que lograram estrear comercialmente têm algo em comum: a parceria com a Argentina desde a fase de produção. É de se observar que são diferentes tipos de parceria, pois no caso de Noches cariocas ela se deu pelo trabalho de artistas e técnicos argentinos ou que haviam atuado naquele país, já El grito de la juventud e Mundo extraño foram iniciativas de produtores brasileiros às quais se associaram empresas argentinas, e, finalmente, No me digas adiós foi uma iniciativa de produtora argentina à qual se somou sua filial no Brasil. A única exceção de novo é Canta Brasil, que não possuía na produção nenhum elemento que o ligasse com a Argentina.

Embora ainda não existisse acordo de coprodução firmado entre Argentina e Brasil ${ }^{26}$, acredito que nos casos de Mundo extraño e No me digas adiós já se pode falar em coprodução, pois a associação entre as produtoras ocorreu desde o início dos respectivos projetos e envolveu capitais, técnicos e artistas de ambos os países.

É significativo perceber que as coproduções internacionais são fundamentais para as tentativas de aumentar, mesmo timidamente, a potencialidade de circulação dos filmes. Isso decorre de que a associação de produtores de dois ou mais países possibilita a exploração qualificada do produto cinematográfico nos respectivos locais, seja porque os produtores tendem obviamente a conhecer melhor o mercado em que atuam, incluindo aí contatos com distribuidores e exibidores, seja porque torna possivel que o filme se beneficie de leis protecionistas, tais como a cota de tela, em mais de um país.

Como anota Thomas Guback (1980, p. 378), a coprodução era uma tendência de diversas cinematografias na Europa iniciada após a Segunda Guerra Mundial e que teve grande crescimento na década de 1950 neste continente. Ou seja, Estudios San Miguel tentou estimular com o Brasil um tipo de associação que então se destacava. Entretanto, em fins de 1951, a empresa encerrou as atividades devido à sua difícil situação econômica (KOHEN, 2000, p. 375). Segundo Pablo Lanza, Jorge Sala e Paula Wolkowicz (2017, p. 104-105), a coprodução não foi uma iniciativa regular por parte dos produtores argentinos no período clássico.

Quanto ao segundo período do recorte proposto, de 1951 a 1954, ele se deve ao fato de

24 Devo a relação dos filmes brasileiros lançados em Portugal a Carlos Roberto de Souza, a quem agradeço pela preciosa informação. 25 Na edição de 1 de agosto de 1951. Heraldo del Cinematografista chegou a estampar anúncio no qual a UCB apresentava Carnaval de fuego. Mas, posteriormente, o periódico não comenta o filme. Pesquisei ainda em La Nación, que cobria todos os lançamentos de Buenos Aires, e também não há referências à estreia da fita. Devido a esses indícios, acredito que o filme não estreou comercialmente na Argentina.

26 O acordo de coprodução entre Argentina e Brasil foi firmado em 1967 (SILVA, 2014, p. 103). 
que o patamar da produção do cinema brasileiro altera-se bruscamente com a fundação, por Franco Zampari, da Cia. Cinematográfica Vera $\mathrm{Cruz}^{27}$, que teve investimento de vultosos capitais da burguesia paulista, permitindo a construção de estúdios, aquisição de equipamentos de ponta e a contratação de diretores, técnicos, atores e atrizes. Dentre os técnicos, os principais nomes eram estrangeiros como montador o Oswald Hafenrichter (austriaco) ou os fotógrafos Chick Fowle (inglês) e José María Beltrán (espanhol que atuou também na Argentina). A Vera Cruz tinha a pretensão declarada de exportar seus filmes, para além de conquistar o mercado brasileiro.

O entusiasmo com a Vera Cruz levou outros empresários a investir em cinema, resultando na criação da Maristela (1950) e da Multifilmes (1952). Embora fossem empresas de menor capital, também pretenderam produzir nos moldes do sistema de estúdios. No caso da Maristela, é importante frisar que foram importados técnicos que atuavam da Argentina: Mario Pagés (fotógrafo), Juan Carlos Landini (operador de câmera) e José Cañizares (montador).

É sabido que nesse periodo melhorou sobremaneira a qualidade técnica do cinema brasileiro. Além disso, alguns filmes destas produtoras fizeram grande sucesso de público no Brasil e chegaram a conquistar prêmios em festivais internacionais, como é o caso das películas da Vera Cruz O cangaceiro (Lima Barreto, 1953) e Sinhá Moça (Tom Payne e Oswaldo Sampaio, 1953).

O contexto fazia supor que a primeira metade da década de 1950 seria um período no qual os filmes brasileiros teriam maior presença na Argentina. Mas, isso não se confirmou. $\mathrm{Na}$ verdade, não há nenhuma película brasileira lançada depois de No me digas adiós até o ano de 1954, ou seja, quando a Vera Cruz encerrou suas atividades tendo à frente Franco Zampari.

Somente em agosto 1955, houve uma nova estreia brasileira, a coprodução da Maristela com a Itália intitulada Magia verde (Gian Gaspare Napolitano, 1955). A Vera Cruz chegou às telas de Buenos Aires apenas em novembro de 1956 , quando, com o título de Cangaceiro, a fita de Lima Barreto foi lançada com distribuição da Columbia.

A dificuldade de acesso da Vera Cruz ao mercado argentino chama atenção para algo que certamente não ocorreu aos seus comanditários quando da criação da empresa, cuja pretensão era produzir filmes "Do planalto abençoado para as telas do mundo" - o lema da companhia. Refiro-me ao protecionismo que, após a Segunda Guerra Mundial, marcou as políticas cinematográficas de diversos países, como a França e a Itália, buscando impedir a dominação absoluta dos mercados nacionais pelo produto norte-americano. Na Argentina, a partir de 1944. instituiu-se a obrigatoriedade de exibição do longa-metragem nacional por meio da Lei 21.344. dentre outras medidas protecionistas. E esse processo se amplificou por meio de instrumentos como a Lei 13.651, regulamentada em 1950:

Para sintetizar o que ocorreu entre os
anos de 1949 e 1952, é possivel dizer que
se observa um aumento da proteção
proporcionada pelo Estado à indústria
cinematográfica, já que esta apresen-
tava os sinais caracteristicos da crise
econômica que se abatia sobre o país ${ }^{28}$
(KRIGER, 2009, p. 69).

Outro dado importante a se ter em conta é o fato de o México, cuja produção era bem maior que a brasileira e já com alguma tradição no mercado argentino, ter diminuido substancialmente a sua presença neste país no periodo de 1951 a 1954. Segundo dados compilados por Nicolás Ezequiel Mazzeo e Jimena Cecilia Trombetta (2017, p. 248), em 1950 foram exibidas dez películas mexicanas na Argentina, número que, em 1951 caiu para duas, em 1952 e 1953 foi a três em ambos os anos, aumentando em 1954 para cinco.

\footnotetext{
27 A Vera Cruz foi fundada em 1949, mas sua primeira película, Caiçara (Adolfo Celi), só começou a ser produzida em 1950 e a estreia ocorreu em São Paulo em novembro do mesmo ano. Ou seja, é impossivel a companhia ter exibido comercialmente algum filme no exterior antes desta data.

28 Do original: "Para sintetizar lo ocurrido entre los años 1949 y 1952, es posible decir que se observa un aumento en la protección brindada por el Estado a la industria cinematográfica, ya que esta presentaba los signos propios de la crisis económica que se abatía sobre el pais".
} 
Outrossim, em Portugal, entre 1951 e 1954, foram lançadas quatro películas brasileiras, todas da Vera Cruz.

Afigura-se que a legislação protecionista adotada pela Argentina afetava os países com pouca tradição no campo cinematográfico, o que levanta efeitos indesejáveis da lei, pois empobrecia a oferta no mercado quanto à origem das produções e, ainda por cima, afastava países com os quais se poderia / deveria estreitar os laços cinematográficos tanto por motivos econômicos quanto culturais.

Ademais, trata-se de um periodo em que os governos se envolviam ativamente nas negociações cinematográficas relativas a outros países. Neste sentido, o ativismo de Raúl Apold à frente da Subsecretaria de Informaciones y Prensa argentina, de ministros e do próprio presidente Perón são exemplares. Mas, no Brasil, o Estado continuava mantendo uma atuação quanto ao cinema bastante desligada de preocupações mercantis e/ou industriais, sem nenhum tipo de ação mais efetiva do governo federal para além de tímidos avanços na cota de tela.

Da mesma forma, mesmo a distribuição da major Columbia não pareceu ajudar muito a Vera $\mathrm{Cruz}^{29}$, afinal a empresa norte-americana aparentemente preferiu comercializar na Argentina primeiro os filmes que havia produzido e depois dava atenção aos produtos dos quais participava apenas como distribuidora.

Toda essa situação revelou-se devastadora, em termos de mercado, para qualquer possivel pretensão da Vera Cruz ou de outras produtoras brasileiras em relação à exploração dos seus filmes na Argentina.

Para concluir, é instigante constatar que, especificamente quanto ao mercado argentino entre 1933 e 1954, a Atlântida teve maior presença do que a Vera Cruz. Além disso, mesmo de maneira muita esparsa, houve experiências transnacionais de tipo variado e, por vezes, surpreendentes, tais como a produção de El grito de la juventud ou o sucesso de público de Mundo extraño. Afigura-se que ainda estão por se fazer pesquisas que apontem para uma dimensão mais realista - e não apenas suposta - da presença do cinema brasileiro no exterior. Como muito da história do cinema brasileiro, talvez alguns mitos se desfaçam após investigações com base em fontes primárias, bem como novos personagens ganhem destaque.

\section{REFERÊNCIAS}

8 DIAS DE CINE. La Película, Buenos Aires, ano 23, n. 1157, p. 6,12 out. 1939.

12 TíTULOS en el programa de San Miguel para la temporada próxima. Heraldo del Cinematografista Buenos Aires, v.18, n. 900, p. 264, 1 dez. 1948.

AUTRAN, Arthur. A guerra gaúcha: o cinema argentino no Brasil (1935-1945). Intercom - Revista Brasileira de Ciências da Comunicação, São Paulo, v. 39 , n. 1, p. 139-158, jan. abr. 2016. Disponivel em: http:// www.portcom.intercom.org.br/revistas/index.php/ revistaintercom/article/view/2359/1954. Acesso em: 20 dez. 2018. https://doi.org/10.1590/18095844201618

AYER: El grito de la juventud. La Nación, Buenos Aires, p. 13, 6 out. 1939.

BORDWELL, David; STAIGER, Janet; THOMPSON, Kristin. The classical Hollywood cinema: film style \& mode of production to 1960 . Londres: Routledge, 1985. https://doi.org/10.4324/9780203358818

CADICAMO, Enrique. Bajo el signo del tango Memorias. 2. ed. Buenos Aires: Corregidor, 1987.

CANTA Brasil. La Nación, Buenos Aires, p. 12, 21 dez. 1946

CANTA Brasil. Heraldo del Cinematografista, Buenos Aires, v. 16, n. 799, p. 229, 25 dez. 1946.

CINEMA Brasileiro. Cinearte, Rio de Janeiro, ano 11 n. 434, p. 21-22, 1 mar. 1936.

COMEDIA sentimental de recursos adocenados es No me digas adiós. La Razón. Buenos Aires, 11 out. 1950

CUATRO estrenos registrará la jornada de hoy. La Nación, Buenos Aires, p. 14, 5 out. 1939.

DI NÚBILA, Domingo. La época de oro - Historia del cine argentino I. Buenos Aires: Ediciones del Jilguero, 1998.

EL EDITOR. En Pocas Palabras. Heraldo del Cinematografista, Buenos Aires, v. 5, n. 217, p. 1.009, 4 set. 1935

29 A Vera Cruz entregou a distribuição da sua produção primeiramente à Universal e depois à Columbia. Coube a esta última distribuidora a maior parte e os mais importantes filmes da companhia, tais como os já citados O cangaceiro e Sinhá Moça 
EL EDITOR. En Pocas Palabras. Heraldo del

Cinematografista, Buenos Aires, v. 6, n. 255, p. 1.187 , 3 jun. 1936

EL EDITOR. En Pocas Palabras. Heraldo del

Cinematografista, Buenos Aires, v. 6, n. 277, p. 1.287 , 4 nov. 1936.

ENEBE. 8 días de Cine. La Película, Buenos Aires, ano 20, n. 974, p. 5-7, 30 dez. 1935.

FABREGAT, E. Rodriguez. Brasil - Otro ejemplo para nuestro cine. Cinegraf, Buenos Aires, v. 5 . n. 51, p. 29 e 43, jul. 1936

GRITO de la juventud, El. Heraldo del Cinematografista, Buenos Aires, v. 9, n. 428, p. 159-160, 11 out. 1939.

GUBACK, Thomas. La industria internacional del cine. Madrid: Fundamentos, 1980.

INDUSTRIA local. Heraldo del Cinematografista, Buenos Aires, v. 5, n. 216, p. 1003, 28 ago. 1935

JOHNSON, Randal. The film industry in Brazil Culture and the State. Pittsburgh: University of Pittsburgh Press, 1987.

KING. Buena mezcla de ficción y realidad en la aventura de Mundo extraño. El Mundo, Buenos Aires, p. 11, 11 mayo 1950.

KOHEN, Héctor R. Estudios San Miguel - Ruletas, películas y política. In: ESPAÑA, Claudio (org.). Cine argentino - Industria y clasicismo - 1933/1956. Buenos Aires: Fondo Nacional de las Artes, 2000. p. 336-385. Vol. I.

KRIGER, Clara. Cine y peronismo - El Estado en escena. Buenos Aires: Siglo Veintiuno, 2009.

LA PEÑA. Chismo Film. Cine Argentino, Buenos Aires, v. 2, n. 75, p. 70-71, 12 out. 1939.

LANZA, Pablo; SALA, Jorge; WOLKOWICZ, Paula. Las experiencias cinematográficas de coproducción entre México y Argentina hacia el final del período clásico-industrial. In: LUSNICH, Ana Laura; AISEMBERG, Alicia; CUARTEROLO, Andrea (org.). Pantallas transnacionales - El cine argentino y mexicano del periodo clásico. Buenos Aires: Imago Mundi, 2017. p. 103-118. https://doi.org/10.4995/thesis/10251/61628

MARIÑO, Cecilia Nuria Gil. Los usos de lo nacional en el desarrollo de un proyecto cinematográfico en Argentina y Brasil en la primera etapa del sonoro. 2016. 247 f. Tese (Doutorado em História) - Facultad de Filosofia y Letras, Universidad de Buenos Aires, Buenos Aires. https://doi.org/10.25145/j. pasos.2017.15.060

MAZZEO, Nicolás Ezequiel; TROMBETTA, Jimena Cecilia. Las políticas de distribución y exhibición en México y Argentina: tensiones e intercambios en la construcción de un mercado transnacional. In: LUS$\mathrm{NICH}$, Ana Laura; AISEMBERG, Alicia; CUARTEROLO, Andrea (org.). Pantallas transnacionales - El cine argentino y mexicano del período clásico. Buenos Aires: Imago Mundi, 2017. p. 235-253. https://doi. org/10.14409/culturas.voig.6155
MUNDO extraño. Heraldo del Cinematografista Buenos Aires, v. 20, n. 976, p. 85, 17 maio 1950.

MUNDO extraño. Mundo Radial, Buenos Aires, p. 45. 18 mayo 1950.

NO ME DIGAS adiós. Heraldo del Cinematografista, Buenos Aires, v. 19, n. 998, p. 253, 18 out. 1950.

NOCHES cariocas. Heraldo del Cinematografista, Buenos Aires, v. 5, n. 234, p. 1.092-1.093,1 jan. 1936.

PELÍCULA MEDÍOCRE diosé a conocer ayer, Una. La Nación, Buenos Aires, p. 12, 24 dez. 1935

PRODUCCIÓN Argentina. Heraldo del Cinematografista, Buenos Aires, v.18, n. 854, p. 9, 14 jan. 1948.

PRODUCCIÓN Argentina. Heraldo del Cinematografista, Buenos Aires, v.18, n. 861, p. 40-41, 3 mar. 1948.

PRODUCCIÓN Argentina. Heraldo del Cinematografista, Buenos Aires, v.18, n. 870, p. 72, 5 mayo 1948.

PRODUCCIÓN Argentina. Heraldo del Cinematografista, Buenos Aires, v.18, n. 879, p. 103, 7 jul. 1948.

SILVA, Hadija Chalupe da. Os filmes realizados em coprodução: limites e expansões de acordos transnacionais. 2014. 309 f. Tese (Doutorado em Comunicação) - Instituto de Artes e Comunicação Social, Universidade Federal Fluminense, Niterói.

\section{Arthur Autran Franco de Sá Neto}

Professor associado no Departamento de Artes e Comunicação da Universidade Federal de São Carlos (PPGIS-UFSCar). Doutorado em Multimeios pela Universidade Estadual de Campinas e Mestrado em Ciências da Comunicação pela Universidade de São Paulo.

\section{Correspondência}

Universidade Federal de São Carlos, Centro de Educação e Ciências Humanas

Via Washington Luis, km 235

Monjolinho

Caixa Postal: 676

13.565-905 - São Carlos (SP) - Brasil 